\title{
Typological Examination of Drawing in Nigerian Art
}

\author{
Razaq Olatunde Rom Kalilu
}

\author{
Hilda Toritsereju Woods
}

\author{
Department of Fine and Applied Arts, Ladoke Akintola University of Technology, Ogbomoso, Nigeria
}

Email: romkalilu@lautech.edu.ng and tojuwoods@yahoo.com

\section{Doi:10.5901/ajis.2014.v3n6p89}

\begin{abstract}
Drawing which predate all other forms of art and verbal language is the focus of this paper. Despite its effectiveness in communication, it has remained rarely analyzed. The study is a typological examination of drawing in Nigerian art. It traces the general history of drawing from pre-historic period to the contemporary times. It further discusses the usage and significance of drawing and examines the various drawing typologies using contemporary Nigerian artistic sphere as a case study. The study is based on direct field investigation and bibliographical data collection from studios, galleries and libraries. Significantly, the study reveals the efficacy of drawing in communication particularly in Nigeria.
\end{abstract}

Keywords: drawing, typology, communication art, Nigerian art

\section{Introduction}

The history of drawing is as old as man. Human beings since prehistoric times have communicated thoughts and ideas through illustrational drawing of objects in their conception of the universe, nature and dreams. They have systematically grown to explore drawing and its attendant possibilities available to them to communicate with the other man and other creatures within their reach, in their immediate environment, and the celestial plane. In fact, human existence and sustenance is centered on their ability to communicate effectively in drawing. There are several anthropological evidences that reveal the strong communicative power of the prehistoric man. These are evident in the different hunting tools and magico-religious drawings and paintings on the cave walls of eastern Europe (Powell, 1973: 7), and in some parts of Africa, particularly Nigeria where it was observed both in her northern and southern parts (Adepegba, 1995). Perhaps the inherent sophistication in drawing by the race occupying the latter region can be attributed to the illustrational prowess of their fore bears. Today in Nigeria, drawing has been modified and integrated into visual conceptualization which cuts across the visual arts, print media and advertising.

Comprehensive writings are few in Nigeria and perhaps in the world. Most of these writings are on usage and significance of drawing as a form of art. Adrewes (1982) in his instruction manual, made illustrations in various media. He taught basic drawing skills and methods and gave practice exercises for students and users alike. He emphasized the usage and significance of drawing in art. Cleaver (1966) and Davidson (2003) surveyed the stylistic evolution and the development of various elements of form, design and techniques of drawing. They also discussed the principles and techniques of drawing. Guptill (1961) also studied drawing with its definitions and the various styles to teaching the art. With several illustrations, it mainly served as an instructional book on pen drawing, its materials and techniques. Shatil's (1995) primary focus was on the psychographic understanding of the child. He addressed, basically, the issues concerning the writing capabilities of the child with medical and physical disabilities. He said that drawing helps a child to make meaningful expressions even when he or she is incapacitated vocally. He went further to analyze the graphic forms and the child's interpretations of natural and artificial objects which they come in regular contact with. It is this psychographic development of children's drawings that will help enhance their writing ability.

Adepegba (1995) highlighted the Nigeria peoples peculiarities in textiles patterning, body adornment and drawing patterns on caves. He observed that the beauty of drawing as a means of communicating symbolic messages is implicitly expressed. The cultural and stylistic importance of drawing, more particularly lines, was the focus of Igboanugo's (1976: 22-28) treatise. He illustrated this with examples from artworks that utilized the Uli motifs. Works of Obiora Udechukwu were used to demonstrate the communication tendencies inherent in the art of drawing. Kalilu (n.d) focused on the foundation to which a technology student must be acquainted with respect to drawing. Drawing, which he claimed to be a 
prerequisite for eventual advancement. He provided a brief history of it and several highlights of the importance of drawing which he defined as "one of the simplest and the same time, complex aspects of art". Kalilu's work also touches on the communicative significance of drawing.

Fosu (1983), in a drawing exhibition catalogue gave an introductory appraisal of Tyron Geter. Again, Fosu (1986: 1-79) in his book gave evidence to art and artist of Africa with peculiar reference to Nigeria. He observed that Nigerians were one of the foremost artists of Africa. He gave analysis of these artists in chronological order. Among those he observed with inherent potential in drawing are Aina Onabolu, Akinola Lasekan, Uche Okeke, Obiora Udechukwu and Erhaboh Emokpae. He however did not acknowledge the drawing prodigy of Nigerian art. Oloidi (1998: 1-9) observed that Aina Onabolu not only left behind ample numbers of drawings but advocated and emphasized the importance of draughtsmanship in the drawing to his students. Oyelola (1998: 20-32) in her contribution to modern Nigerian art also observed that drawing is evident in Agbo Folarin's lithographical illustrations. Amoda (2003: 1-23) in his exhibition catalogue decried the unprecedented neglect of drawing by artists and in the art training in contemporary art schools in Nigeria. He however, reiterated the need for the rejuvenation of drawing.

None of the literature reviewed categorically focused its discussion on the importance and usage of drawing as a vital communication tool in communication arts. There has not been a sole study on broad usage of drawing in our dayto-day encounter in Nigeria. It is therefore, expedient to study the role of drawing in arts in relation with other human endeavours, and provide a detailed analysis of its usage and significance in Nigeria.

\section{Drawing in Nigeria}

The Twentieth Century is definitely significant in the history of art not only in the plethora of documents, but because it brought African art and more importantly Nigerian art (Willet, 1963: 3) and artist into global fame/reckoning. Among the artists who made fame in art and in drawing between the dawn and the middle of the century in Nigeria are Aina Onabolu and Akinola Lasekan, both were acclaimed first generation artists with Western orientation (Fosu, 1986: 6-8). In the words of Oloidi (1998: 5), he argued that Onabolu made hundreds of lead pencil or charcoal studies of his models, in spite of the latter claim; Onabolu's prowess was more obvious in portraiture paintings than in drawing. Lasekan on the other hand, was acknowledged the first Nigerian cartoonist and the un-celebrated father of modern Nigerian drawing with his satiric drawings in cartoons. According to Fosu (1968: 8), among Lasekan's drawings are the provocative cartoons of Poor Africans and the Blackman at the West African Pilot. Lasekan proficiency was further justified with the four books of cartoon drawings he published in the 1940's (Fosu, 1968: 8).

Their efforts arguably influenced directly or indirectly the likes of Ben Enwonwu in the 1940's and the conglomerates of students' of the Zaria art school, who were later known as the 'Zarian Rebels' in the late 1950s (Fosu, 1968: 45-60). There is no doubt that drawing would be inherent in all of them, it was only Uche Okeke that truly excelled in drawing and it is so evident in his Uli experiment, also known as Ulism. Okeke's drawings are often rendered in carbon pencil, pen and ink, charcoal or gouache with titles such as Ojadili, The Orphan and The Maiden's Cry. Okeke's influence has rubbed off on Obiora Udechukwu who later became an apostle of the Uli symbols in art. In the words of Fosu (1968: 69), Udechukwu's works are marked by line drawing in which Right on Brother and Wait or Drink from the Gutter was apparent examples.

The late 1970's and 1980's were unarguably one of the most vibrant periods in the history of modern art in Nigeria (Oyelola, 1998: 21). Because it witnessed and embraced the emergence of more art training institutions in the country which automatically turned out more academic oriented artists like never before, it also saw to the rejuvenation of drawing with an attendant exhibitions in the visual arts and its diversification into other medias (like the Newsprint and the Advertising industries). Artists of significant and traceable records in drawing during these eras were the likes of Agbo Folarin, Tyron Geter, Josy Ajiboye, Hilda Woods, Ebun Aleshinloye, Sola Ogunfuwa.

Folarin (Oyelola, 1998: 24) and Geter (Fosu, 1983: 3), were lecturers in two notable Nigerian Universities, although Geter was not a Nigerian, his drawing experiments were said to have been rekindled during his residency at the Ahmadu Bello Universities, Zaria where he held two outstanding exhibitions entitled footnotes: An exhibition of Paintings and Drawings and Vibrations: Harmonious Discords of Space Exhibitions of Paintings and Drawing in 1983 and 1986 respectively. His drawings particularly that of Gani Odutokun's portrait in the 1983 exhibition can be described outstanding for its fluidity in his use of charcoal (Fosu, 1983: 27). In the case of Folarin, Oyelola (1998: 24-26), observed that he is vividly remembered for the preparatory drawings of Ogun and Osun the Yoruba god and goddess which were used for his Orisa lithograph series in 1979 and 1980.

Jossy Ajiboye's pedigree in cartoon illustrations in the newsprint is traceable to the pioneering role played by 
Lasekan. Although, Ajiboye have started drawing before the 1980s, prominence of his works became more evident in the 1980s, particularly for his ingenious crystallization of the political and economic instabilities of the period into satiric cartooning on the pages of the Nigerian Daily Times where he worked. He also had to his credit a book on cartoon titled Jossy Ajiboye on Sunday; an amalgam of some of his contributions to drawing. However, Ogunfuwa falls in the category of younger generation of artists. His drawing illustrations on the pages of two Nigerian dailies precisely the Guardian and the National Concord were still apparent in the archives of these newspaper houses. There is no doubt that the 1980's witnessed plethora of drawing illustrations by other illustrators whose names were not mentioned in this findings.

The Advertising industries were also not left out in the action of drawing as it formed the basis for any meaningful advertising design. Lintas ranked among the first generation of advertising agencies in Nigeria and by the 1980's the numbers of these agencies had risen to 23 with Rosabel and Insight communications waxing stronger. All these agencies have visual artists who help in drafting story board of any advertorial design in form of illustrations. Notable among such artists was Erhabor Emokpae who rose to the post of the head of design section of Lintas, Lagos in the 1980's. However, there is no doubt that the impression of drawing in the 1980's necessitated it's diffusion in to educational publications in the 1990's and the 2000's. These revelations are informed of colourful drawing illustrations on the Pages of most kindergarten, primary and Junior Secondary school books. Macmillan and Oxford publications are some of such materials. Most of these publishing houses now host visual illustrators who draw for them.

\section{Drawing Typology}

The apparent drawing typological classification in Nigeria with respect to technique and stylistic variables are six; they are classic, suggestive or gestural, illustration, cartoon, advertorial and symbolic. These typological categories are, however, dictated by the Nigerian communication arts environment. Selected drawings of the latter type categories are consequently discussed.

\subsection{Classic}

Classic drawings within the scope of this research are drawings of undergraduate and postgraduate art students of tertiary institutions, art teachers and lecturers and formal trained practicing artist. The works rendered in the so called perfect state (with some degree of resemblance) are executed in various media and are of different themes. The works analysed under classic include portrait drawing, landscape, still life, figure and figures in a setting drawings. 'Self Portrait' (plate 1) is rendered in ink on cartridge paper, the shading techniques prominent in the portrait include hatching, crosshatching, doodling and smudging. The combination of these techniques, though used for an adult, ensures softness and subtlety. The strong highlight on the face also tends to make the face gay. Plate 2 is a charcoal landscape drawing with suggestive lines boldly employed to form recognizable objects that is: buildings and trees. Contour lines are effectively used in depicting the road and ground surfaces. The successful use of chiaroscuro and the omission of certain edges make the drawing lively and interesting. As for the still life drawings (plates 3), objects are interestingly composed and drawn. The objects in the compositions include box, table, shelf, cylinders, buckets, cans and gourd. It is skillfully rendered in pencil on paper with blurring shading technique. Another remarkable drawing is that of Emmanuel Inuk's "Body painting" done on canvas in woolly thread (plate 4). The artist through scrolling drew two female figures in wool; a clothed female figure is seen painting the body of another female that is depicted in nude. He creates shades and tones on the figures by concentrating the wool on the desired areas as is seen in the upper arm and below the breast of the nude. Wool is also used as thin, wavy lines in the shading of the skin surface. The artist employed the scrolling techniques for the wool in his rendition. 


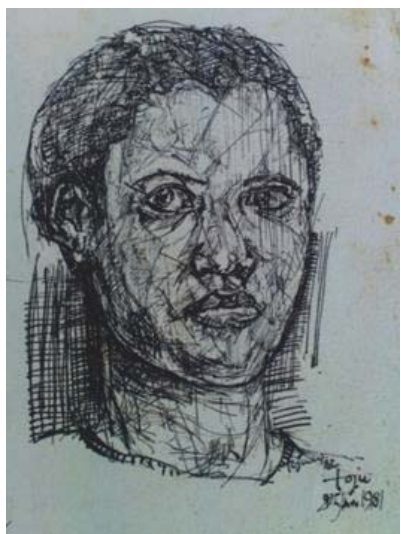

\section{Plate 1}

Hilda T. Woods, Self portrait, ink on cartridge paper, $13.3 \mathrm{~cm} \times 10 \mathrm{~cm}, 1981$.

Photograph by Hilda T. Woods, 2009.

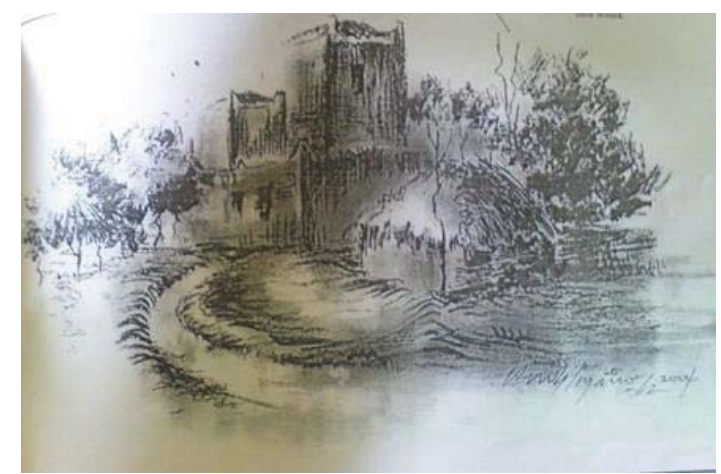

\section{Plate 2}

Umoh Inyang, Gida Sarki, Charcoal on paper, 20x30cm, 2004.

Lines Speak, An Exhibition of Contemporary Drawings, 2004, 79.

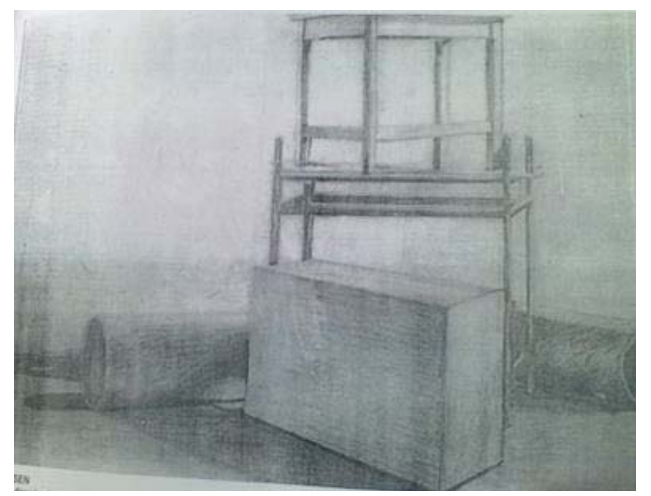

\section{Plate 3}

Uwah Usen, Object Drawing, pencil on paper, 20x15cm, 1982.

Lines Speak, An Exhibition of Contemporary Drawings, 2004, 98. 


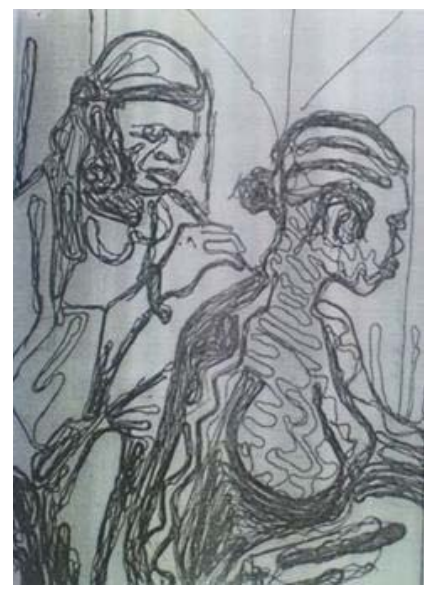

\section{Plate 4}

Emmanuel Inuk, Body painting, wool on canvas, 56x77cm, 2004.

Lines Speak, An Exhibition of Contemporary Drawings, 2004, 78.

\subsection{Suggestive}

Suggestive drawings, as the name implies, refers to that drawing which indirectly or sketchily reveals the subject or theme. Drawings in this communication box include abstract drawings and line drawings, as well as sketches and child art. A child's drawing (plate 5) mostly exhibits the child's inner thoughts as perceived for other people to ponder on. Such drawings demonstrate the child's creative ability between the ages of two and twelve (that is, before they reach their teens). Child art of the crèche is basically scribbles, which are mostly symbolic or suggestive. The child artist battles the usual control of lines; however, as he grows, the scribbles develop into pre-schematic drawings (semi-representations and recognizable objects). Similarly, line drawings display line movements which do not necessarily have to represent definite and recognizable objects but rather suggest objects (plates 6 and 7). Most often from line drawings, the observer can make intelligent guesses. Sketches on the other hand are simple, gestural drawings made quickly and without details (plate 8). Sketches, most often are outlines of the natural form of an object. There are also abstract drawings which neither represent people nor things in a realistic way but express the artist's ideas about them (plate 9).

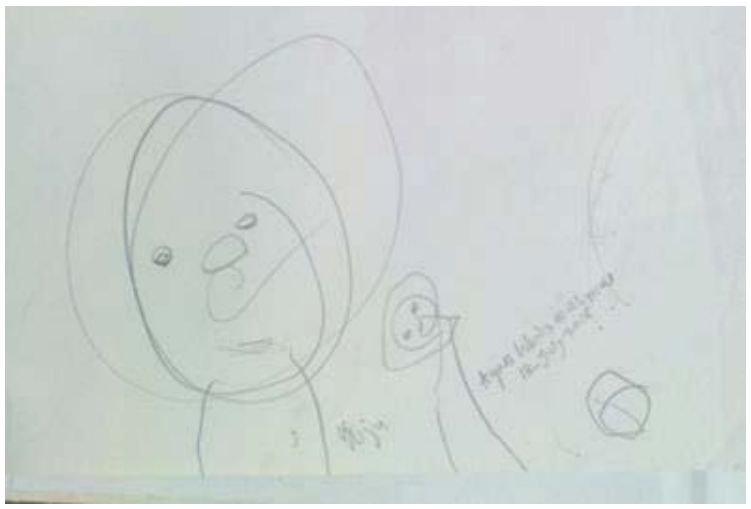

\section{Plate 5}

Agnes Woods, Woman, pencil on cartridge paper, 29x18cm, 2008.

Photograph by Hilda T. Woods, 2009. 


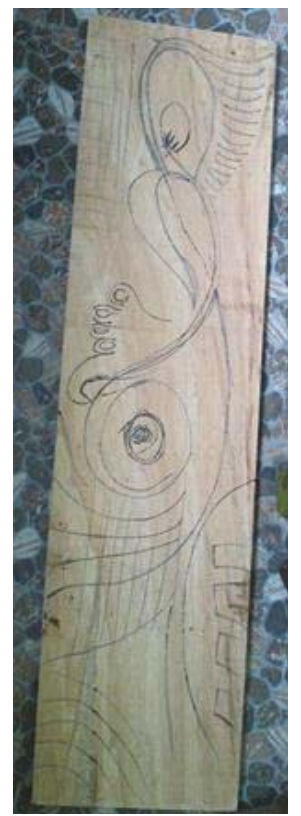

\section{Plate 6}

Hilda T. Woods, Drum lines, Wood, 30x122cm, 2009.

Photograph by Hilda T. Woods, 2009.

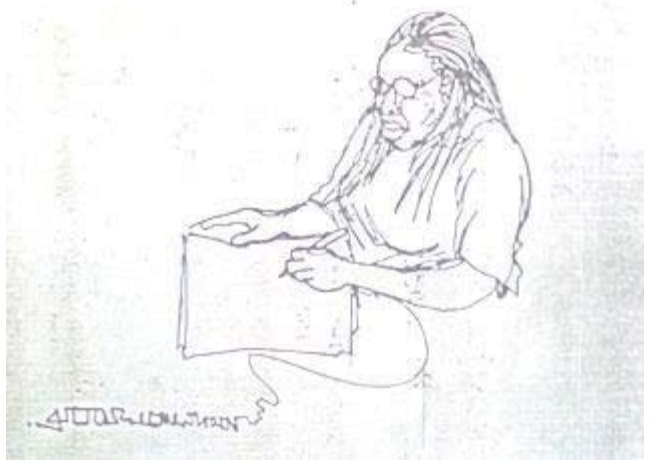

\section{Plate 7}

Idongesit Udi, Continuity in space study 1, pen and ink on paper, 46x41cm, 2004.

Lines Speak, An Exhibition of Contemporary Drawings, 2004, 52. 


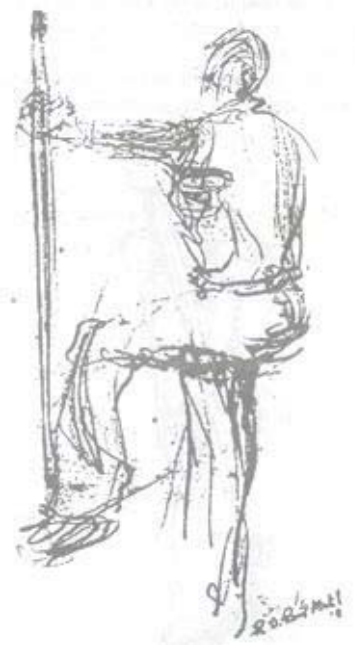

Plate 8

R. O. Rom Kalilu, Standing figure, pencil on paper, 1984.

R. O. Rom Kalilu, n.d., 24

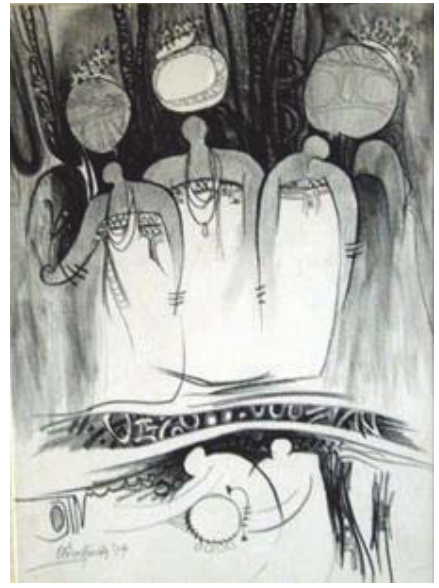

\section{Plate 9}

Sola Ogunfuwa, Arugba, charcoal on paper, 30x40cm, 2004.

Photograph by Hilda T. Woods, 2009.

\subsection{Illustration}

Illustrations are drawings mostly employed in book, magazines etc, especially introduced to buttress or highlight ideas visually. Commonly, illustration drawings are found also in teaching aids. Plate 10, however, is the illustration of an extended family. The illustration depicted the family members in their various age groups rendered in lines and ink wash in naturalistic forms of in less-amusing cartoon characters. Scientific illustration drawings are basically diagrams and charts, often rendered in simple lines of uniform thickness without any form of shading. Drawings used as teaching aids, especially at elementary levels are often drawings of common objects found in the environment which the audience is conversant with (plates 11). They are usually accompanied by explanatory texts. 


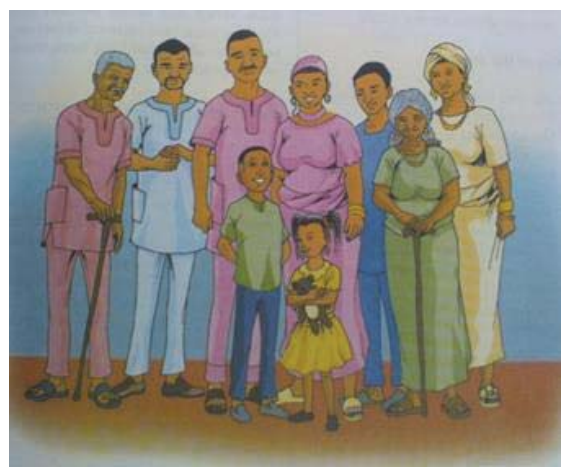

\section{Plate 10}

\section{Extended Family}

Courtesy: Anikpo et al, Basic Social Studies for Junior Secondary School 1, Longman Nigeria plc, Lagos, 2007:21.

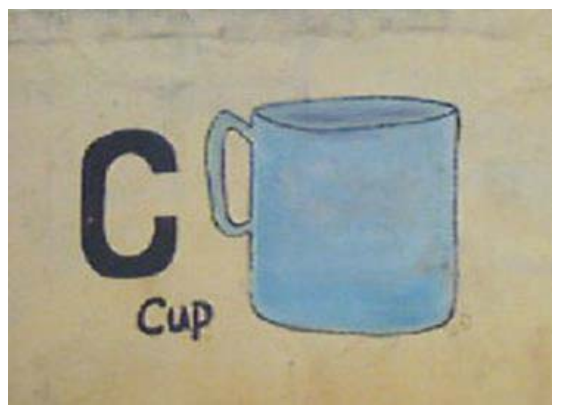

\section{Plate 11}

\section{Teaching aid}

Photograph by Hilda T. Woods, 2009.

\subsection{Cartoon}

Cartoons, which are usually caricature-like, are amusing drawings mostly found in the newspapers and magazines. They regularly delve into Politics, sports or events of everyday occurrence. Cartoons satirize societal ills like lack of electricity, substandard goods and electoral malpractices. Plate 12 is an outline caricature drawing on election malpractice. The cartoon depicts the personalities of two former Nigerian presidential candidates of the People Democratic Party (PDP) and the All Nigerian Peoples Party (ANPP) in a boxing ring. Olusegun Obasanjo, the PDP candidate's hand is raised up in victory over Buhari Mohammed, the ANPP candidate who has been physically battered. The accompanying text conveys a possible fraud by the referee in his weight of justice and fair play. The referee represents the Independent National Electoral Commission (INEC) officer. The cartoon is executed in pen and ink wash with lines of varying thickness effectively used to depict varying different moods. 


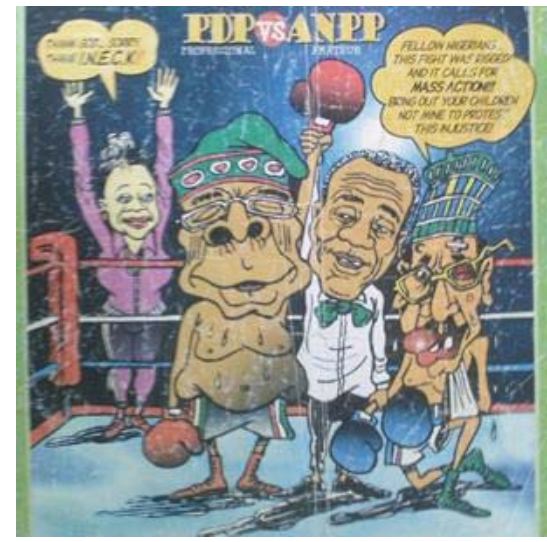

\section{Plate 12}

Cover Illustration, PDP vs ANPP, pen and ink.

Kalabash Monthly Newspaper, Issue 05, 2003.

\subsection{Advertorial}

Advertorial drawings are found on posters, bill boards, magazines newsprints, etc. They tell the public about a product, service, business or programme, in order to encourage people to buy, sell, use or participate as the case may be. The drawings may be naturalistic, abstract or stylized. The information conveyed by the drawing is often complimented with text. The programme advertorial of 'A Nite of A Thousand Laughs' (plate 15) shows drawings of laughing faces rendered in line, which further justifies the comedic nature of the programme. Stylized caps from the three major ethnic groups in Nigeria (Hausa, Igbo, Yoruba) are placed on their heads. The music notes at the background suggest music performances while the vertical lines and bubbles are suggestive of a joyful mood. At the top right hand corner of the advert is a green and white flag with the inscription "Proudly Nigerian" indicating its Nigerian origin. The artist has displayed skills which suggest he must have had formal art training to some reasonable degree.

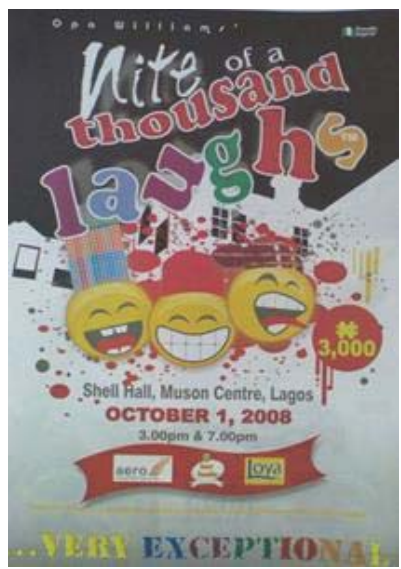

\section{Plate 13}

A Nite of A Thousand Laughs, ink on paper.

City People, September 172008.

\subsection{Symbolic}

By symbolic drawings, the research refers to drawings with contextual meanings. Here, signs and motifs depicted in 
drawings communicate certain messages which may or may not be universally understood or interpreted. Tattoos, scarifications and native printed fabrics are among the various media where different motifs are commonly exhibited. Most scarifications are permanent. Animals (plate 14), plants, geometric shapes and other elements of nature are prominent motifs on scarified body parts. Its symbolism ranges from pure beautification, through magical and identification to medicinal purposes. Tattoos, though sometimes permanent; is mostly temporary body decoration. Among the motifs drawn on body parts such as the arm, chest, back, hand and waist are those of sea horse, human figures, flowers, moon, sun, love, heart, etc. some other tattoo drawings are in text. Tattoos are expressions of the wearers' fantasies, ideologies and philosophies. Varied animal motifs found on nature printed fabrics include lizards of different kinds, chameleon, snail, snake, bat, ostrich and birds. Other motifs include cassava leave (plate 15), comb, crown, fan, fish, tree, talking drums and calabashes. Most of the motifs carry their natural names and may come in repeat patterns on the fabric. The motifs, basically drawn for design purposes are of objects found in nature but are rendered in abstract form with emphasis on geometric shapes.

Road signs are also very common example of symbolic drawings. They communicate information that guides road users, prevent accidents and ensures safety on the road. A road sign indicating children crossing shows the drawing of children in silhouette, leading themselves by hand (plate 16). Some road sign drawings symbolize Sharp Bends, Stop, One Way and Two Way Traffic, No Left Turn, No -"U" Turn, No Stopping, T junction and Round About, zebra crossing among other symbols. However, most road sign drawings are rendered in silhouette.

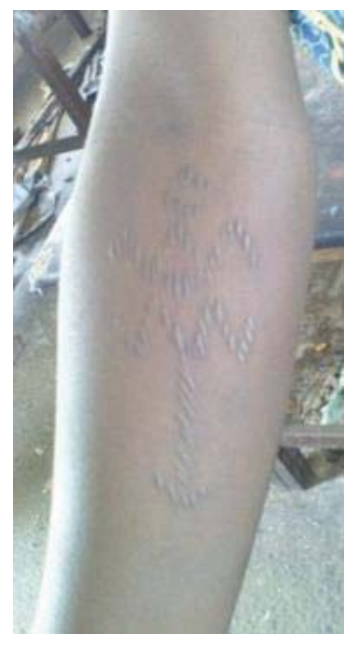

\section{Plate 18}

Lizard (body painting)

Photograph by Hilda T. Woods, 2009.

\section{Plate 20}

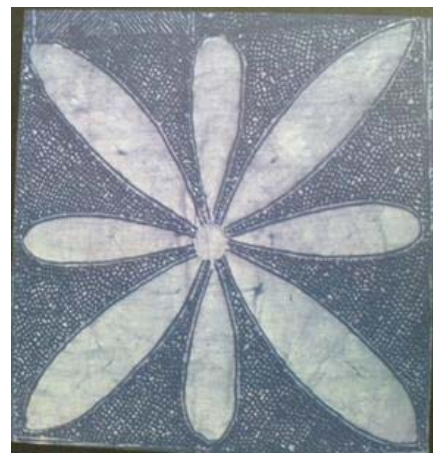

Ritka Carr, Cassava leaves ('Ewe Ege'), dye on fabric. Mayowa Falas, Beyond Indigo, 2001 


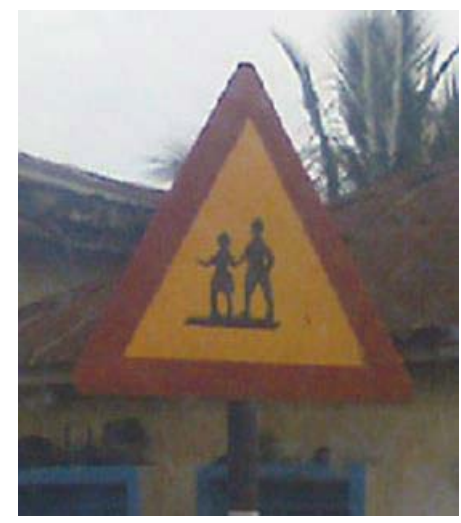

\section{Plate 21}

Children Crossing

Photograph by Hilda T. Woods, 2009.

\section{Significance and Prospects}

Drawing is the basic foundation of any form of the visual arts; it is used in communication, apparently evident in the caves and rocks monochromatic paintings or drawings of Africa and Europe (Willet, 1971). These drawings gave abundant information on the civilization of Africa. Drawing in Nigeria is an integral part of the people's culture. A good example is the Uli body decoration which was modified by the Nsukka School into Ulism. Significantly, drawing trains the mind, eye and the hand; for instant, it helps in the coordination of mental activities and expands one's visual vocabulary, aesthetic appreciation and above all, seeing beyond the surface value of artistic creation. It is commonly referred to as a visual language, basically because it is a means of communication. As a visual language, it is universally understood, thus breaking cultural, linguistic and social barriers. For instance, a drawing of a house is understood and interpreted as a house anywhere around the globe. Exploratory drawings give visible form to one's ideas for others to ruminate on. Drawings are used explicitly to transmit messages or convey information. It speaks volumes in a very small space. The influence of drawing is felt in many if not all facets of human creativity. It is not restricted to art since technological productions have their initial development based on technical and freehand drawings. Drawings can be descriptive, narrative, explanatory and expository. Obiora Udechukwu's drawings gave an exposition of events in the South eastern region of Nigeria during the Nigerian civil war between 1967 and 1970. Drawing is an intellectual exercise by which the individual is trained to observe and think plastically in terms of dimensions and space. Whichever way it is viewed, one fact remains constant, drawing communicates.

\section{Conclusion}

The communicative quality of drawing is made simple through illustration, description, narrative and documentation. In Nigeria, drawing in arts is seen mainly as a visual way of expressions and it include book illustrations, billboard advertisement, TV animation and cartooning. Drawing has thus become one of the most vital tools in arts. It involves the use of almost all available drawing techniques found around the globe. Drawing entails the use of principles and elements of design in bringing out the essence of the object represented. Some types of drawings are still life, nature, figure, seascape, landscape and imaginative drawings. The common materials used in drawing includes pencil, charcoal, pastel, chalk, pen, ink, crayon, drawing board, water colour, gouache, gum and paste medium, scalpel, smugger and wax. The surfaces to be drawn on may be paper (bond, cartridge, cardboard and sugar) or fabric. The typologies however, are classic, suggestive, illustrative, cartoon, advertorial and symbolic drawings. Drawing supplies abundant information in history and civilization of a people as is the case in Nigeria and Africa. As a communication tool, it contributes to the effective communication of other visual arts specialization areas, as it is the basic foundation of any form of the visual arts. 


\section{References}

Adepegba C.O. (1995). Nigerian Art: It's Traditions and Modern Tendencies. Ibadan: Jodad Publishers.

Amoda, O. (12th Dec.-31 Dec. 2003). Oscillating between the Ideal Form and Functional Necessities: An Exhibition of Figure Drawings by Olu Amoda. Lagos, Nigeria: CCF.

Andrewes, E. (1982). A Manual For Drawing And Painting. 3rd Impression. Kent, UK: Hodder and Stoughton Educational.

Gowing, L. (2005). Britannica Biographical Encyclopedia of Artist. Volume 1-3. London: Encyclopedia Britannica

Gowing, L. (2005). Britannica Biographical Encyclopedia of Art. Volume 1-3. London: Encyclopedia Britannica

Cleaver, D.G. (1966). Art: An Introduction. Harcourt: Brace and World Inc.

Ching, F.D.K. (1990). Drawing: A Creative Process. Van Nostrand Reinhold.

Davidson, M. (2003). How to Draw and Paint Texture. Quarto Publishing Ltd.

Fosu, K. (1983). Footnotes: An Exhibition of Paintings and Drawings by Tyrone Geter. Zaria, Nigeria: Department of Fine Arts, Ahmadu Bello University. pp 3-6.

Fosu, K. (1986). 20 $0^{\text {th }}$ Century Art of Africa. Zaria: Gaskiya Corporation

Guptil, A.L. (1961). Drawing With Pen And Ink. Revised Edition. Van Nostrand: Reinhold Company.

Hauser, A. (1962). The Social History of Art: Renaissance, Mannerism and Baroque. Volume 2. London: 'Routhedge and Kegan Paul Ltd.

Ian, S. (1991). The Encyclopedia of Drawing Techniques. London, New York, Sidney, Toronto: Headline Book Publishing Plc.

Idiong, S. (2004) "Contour Drawing." In Line Speaks: An Exhibition of Contemporary Drawing. Nigeria: Society of Nigerian Artist (SNA) and National Gallery of Art (NGA).

Igboanugo, P.S.C. (1976). "Homage to Christopher Okigbo, An exhibition by Obiora Udechukwu", Nigeria Magazine, No. 120. pp. 22-28. Jonathan, S. (1995). The Psychograph of The Child, University Press of America Inc.

Kalilu, R.O.Rom. (n.d). Fundamentals of Drawing. Ogbomoso, Nigeria: Department of Fine and Applied Arts, LAUTECH.

Oloidi, O. (Jan. 1997-Dec. 1998). Onabolu, Pioneer of Modern Art in Nigeria: An Introduction. USO: Nigerian Journal of Art. pp 1-9.

Oyelola, P. (Jan. 1997-Dec. 1998). Internationalism and Ethnicity in Modern Nigerian Art. In USO: Nigerian Journal of Art. pp 20-23.

Powell, A. (1973). The Origins of Western Art. London: Thames and Hudson Ltd.

Stokstad, M. (1995). Art History, Volume 2. New York: Prentice Hall, Inc., and Harry N. Abrams, Inc., Publishers.

Willet, F. (1971). African Art: An Introduction. London: Thames and Hudson. 